\title{
URINARY InCONTINENCE IN FEMALE PATIENTS With Chronic Obstructive Pulmonary Disease
}

\begin{abstract}
Background: Urinary incontinence has been experienced as a problem since $1500 \mathrm{BC}$. In the twentieth century it is still a major problem that remains a source of distress for many sufferers. A lack of literature regarding the prevalence of stress urinary incontinence (SUI) amongst chronic obstructive pulmonary disease (COPD) patients lead to this study. Objective: To determine the prevalence of stress urinary incontinence in female COPD patients between the ages of 30 and 70 years.
\end{abstract}

PAPADOPOULOS $M^{\prime}$; MULLER I; CULLEN S

'Lecturer in Physiotherapy, Department of Physiotherapy, University of the Witwatersrand.

Methods: This cross-sectional study included 67 female COPD patients (aged 30-70 years) who were interviewed during a three month period. A structured COPD / incontinence questionnaire was used to obtain data. Statistical analysis of results included Fisher's exact test and two-tailed t-tests. A p-value of <0,05 was considered to be statistical significant.

Results: The prevalence of SUI in female COPD patients was estimated as 82,1\%. Smoking history was the only variable with a significant positive correlation regarding the patients presenting with $S U I(p<0,05)$. The proportion of smokers in the subjects presenting with SUI (SUI group - 29/55) is significantly higher than the subjects with no symptoms of SUI (normal group - 2/I2).

Discussion and Conclusion: The outcome of this study revealed a high prevalence of SUI in female COPD patients. Cigarette smoking, as the major contributing factor, revealed a strong statistical correlation between COPD and SUI.

KEY WORDS: CHRONIC OBSTRUCTIVE PULMONARY DISEASE; URINARY INCONTINENCE: STRESS URINARY INCONTINENCE; PREVALENCE; CIGARETTE SMOKING

This study was completed in partial fulfillment of the B PhysT degree, University of Pretoria.

CORRESPONDENCE TO:

M Papadopoulos, Department of Physiotherapy, University of Pretoria, P.O. Box 667, Pretoria 0001. Tel: (012) 354-2023.
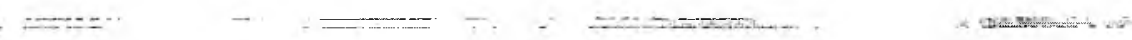

\section{CHECK OUT \\ THE SASP'S \\ WEBSITE AT}

www.physiosa.org.za

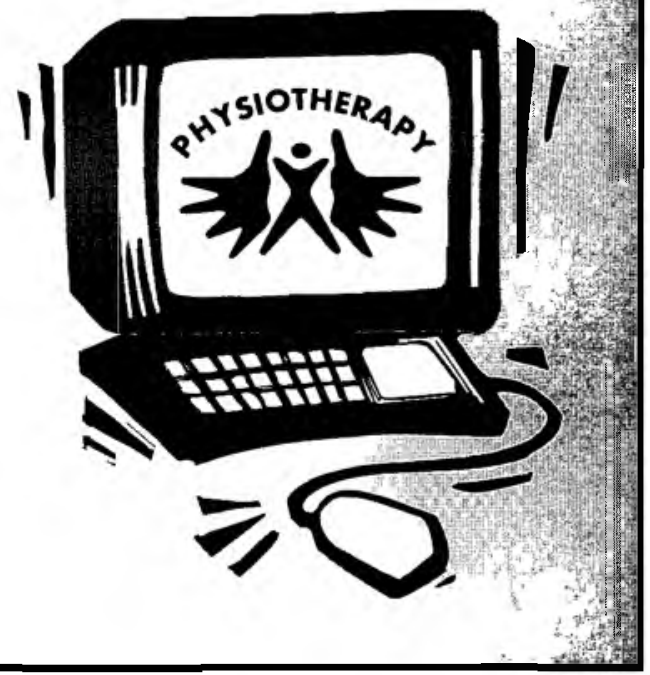

